Arqueología y Sociedad,

№ 20, 2009

\title{
SOBRE LAS FORMAS DE SEPULTAMIENTO PREHISPÁNICO EN Kuelap, AMAZONAS
}

Arturo Ruiz Estrada*

\section{Resumen}

Se presenta las formas de sepultamiento identificadas en el complejo arqueológico de Kuelap, provincia de Luya, región de Amazonas, Perú. Dichas tumbas comprenden seis categorías de repositorios funerarios entre las cuales se mencionan sepulcros en nichos, chullpas, fosas, sarcófagos, mausoleos y grutas. El hecho de existir formas mortuorias diferentes debe estar ligado a la posición social de los difuntos y a diferentes momentos en la historia del sitio. La forma de las sepulturas y sus asociaciones indican que ellas fueron construidas entre los siglos X al XV después de Cristo. Durante este tiempo, según los datos históricos, Kuelap fue habitado por un grupo humano integrado a otros de la antigua provincia de Luyaychillao, contemporánea de los Chachapoya, Chilcho y otros todavía no bien identificados.

\section{Palabras Clave}

Arqueología / sepulturas / Kuelap / Amazonas / Perú

\begin{abstract}
The present paper deals with burial patterns identified in the archaeological complex of Kuelap, in the Luya province, within the Amazonas region, Peru. Such burials represent six categories of funerary repositories among which are mentioned niches, chullpas, underground tombs, sarcophagi and caves. The fact that there are several burial patterns would seem to be linked to the social status of the deceased and to different periods for the site and its history. The shape of the burials and their associated elements indicate they were built between the fifth and fifteenth century A.D. During this time, according to historical data, Kuelap was inhabited by a human group integrated to others in the ancient Luyaychillao province, which at the same time was contemporary to the Chachapoya, Chilcho and other not yet identified groups.
\end{abstract}

Keywords

Archaeology / Burials / Kuelap / Amazonas / Peru

* Universidad Nacional Mayor de San Marcos.

Correo electrónico: aruizestrada@yahoo.com 


\section{INTRODUCCIÓN}

Además de las edificaciones de carácter cívico, religioso y militar que contiene el complejo arqueológico de Kuelap, se observa también en él, varios tipos de estructuras mortuorias, cuya identificación es necesario señalar, para comprender las costumbres funerarias antiguas de la región de Amazonas. La destrucción que ha sufrido Kuelap a través del tiempo impide tener una idea completa de la naturaleza de tales vestigios, pero los restos todavía en pie dan algunos indicios para tratar de examinar un aspecto de la cultura local vinculada a la muerte. Las antiguas costumbres funerarias fueron articuladas por los pobladores locales como una forma de integrar a los muertos en su grupo social. En ese sentido, ellos elaboraron sus propios rituales durante las exequias así como erigieron estructuras funerarias en concordancia a la organización social imperante. Por tal motivo, nos proponemos anotar las diferentes modalidades de sepultamiento, toda vez que otras expresiones materiales identificadas en el lugar, como por ejemplo la alfarería, no ofrecen ilustraciones relacionadas con la muerte y los enterramientos, como si es ostensible en otras culturas como la Mochica, por ejemplo. También es de nuestro interés comprender las formas de sepultamiento, por cuanto uno de los aspectos que llama la atención de las culturas pre-inca de Amazonas tiene relación con la existencia de espectaculares sarcófagos y mausoleos colocados en acantilados abismáticos. A estos restos se atribuye, de modo general, ser las únicas modalidades de los patrones funerarios, habiendo en cambio, otras formas de enterramiento, como ocurre en el caso del complejo de Kuelap. Por otro lado, debemos tener presente la importancia de Kuelap en el contexto de los pueblos que ocuparon las regiones de Amazonas y San Martín, por ser uno de los centros arqueológicos mas extensos del Nor-oriente peruano y de la selva amazónica en general. En los tiempos de su vigencia, tal complejo monumental, por la posición estratégica que presenta, ubicado en la ceja de selva, debió cumplir el rol de intermediario en las relaciones de la región costeña con la sierra y la selva baja. Así como también se ha reportado para el caso de Pajatén, otra urbe de gran importancia, cuyos materiales arqueológicos identificados muestran, igualmente, una amplia red de intercambios de larga distancia con las áreas ya indicadas. (Church, 2002: 24; 1996).

Últimamente, se va tomando en cuenta el estudio de la muerte en el territorio andino, de forma más consistente, desde cuando se produjo el hallazgo y registro adecuado de tumbas y cementerios. A ello se añade la elaboración de ideas y metodologías para comprender con mayor amplitud las implicancias que ocurrían al producirse el deceso en tiempos prehispánicos (Kaulicke 2000). Esta situación impulsa al mismo tiempo afinar las tareas de los trabajos de campo cuando se enfrenta la excavación de una tumba o un cementerio, así como en las expediciones exploratorias.

Teniendo en consideración lo antes anotado, versa nuestra información sobre la distinción de las formas de sepultamiento identificadas en Kuelap, para que sirva como asidero a futuras investigaciones en la región. Esas modalidades funerarias, además, constituyen indicadores de la conducta de quienes ocuparon dicho complejo arqueológico, toda vez que adquieren sus propias particularidades. Son entonces estas particularidades las que posibilitan inferir algunos aspectos de la organización social y las complejidades de los ritos mortuorios. De todo ello resulta interesante la posibilidad de asignar los tipos de sepultura a cada una de las unidades sociopolíticas que ocuparon el territorio de Amazonas mucho antes de la presencia hispana en el siglo XVI. Debemos advertir que no abordamos el estudio de los aspectos internos o del contenido de las tumbas, en vista de haberlas encontrado disturbadas. Un estudio de tal naturaleza nos hubiera servido 
para discutir e identificar los patrones funerarios que ocurrieron en Kuelap.

\section{EL COMPLEJO ARQUEOLÓGICO}

Los monumentos de Kuelap, se erigen sobre una enorme formación rocosa del mismo nombre, que se alza desde la margen izquierda del río Utcubamba, y está ubicado en los territorios del anexo de Kuelap, distrito de El Tingo, provincia de Luya, región de Amazonas. El anexo involucra el complejo arqueológico y una comunidad de pobladores actuales que habitan allí, desde tiempos inmemoriales. El conjunto central, denominado la Fortaleza de Kuelap ocupa un sector alto del macizo y, a su entorno, se distribuyen varios sectores vinculados a él. En estos sectores existen restos arqueológicos cuyas características arquitectónicas tienen relación con el mencionado conjunto central. También se distingue en la superficie de ellos, muchos fragmentos de alfarería emparentada a varios tipos pertenecientes a la Fase Kuelap.

Los sectores distribuidos en Kuelap, aparte de la Fortaleza del mismo nombre, son los de la Fortaleza de Malca, ubicada inmediatamente al Sur, que muestra estar inconclusa, pero es de similares características a la anterior, porque incluso conserva una Entrada Principal que mira al Oeste. Más al Sur de Malca, en una pequeña colina, se halla el sector de Churpunta con terrazas que seguramente estaban destinadas a labores agrícolas. Al Norte de la Fortaleza se encuentran el sector de La Fila, con una gran plataforma que nos parece estuvo destinado a cumplir funciones defensivas, por el hecho de estar localizado en la parta mas alta del macizo rocoso. Otro sector es el los Abrigos rocosos con restos de sarcófagos antropomorfos deteriorados, uno de ellos en dirección de la tercera entrada nombrado La Petaca y otro mas al Norte en el abismático acantilado occidental. La Barreta, constituye el sector donde se conservan dos mausoleos construidos en el farallón rocoso que mira al pago de Ucsul.
El sector de Pampalinda, situado al Este de los sectores anteriores, conserva varias edificaciones circulares, adyacente a varias terrazas. En la misma dirección, pero mas alejado, se encuentra el sector denominado Imperio donde se observan estructuras de planta rectangular y alfarería asociada de estilo Inca. Este sector corresponde a la etapa de ocupación cusqueña del complejo. Otro conjunto, viene a ser el sector nombrado Jesú, donde aparecen varias estructuras circulares, similares a muchas de las edificaciones del interior de la Fortaleza de Kuelap. Mas al Oeste de Jesú ubicamos el sitio de Pumahuanchina con un importante basural arqueológico. San José, es también un conjunto con restos de cimientos de recintos y terrazas. Finalmente, Lirio, que viene a ser un sector con similares características que el de San José.

La altitud señalada para Kuelap varía entre los 2500 a 3000 metros sobre el nivel del mar y corresponde a la denominada zona quechua, que en esta región adquiere sus propias características climáticas y fitogeográficas lo cual permite incluirla en la franja de los denominados bosques de neblinas.

\section{ANTECEDENTES}

Se tiene conocimiento de Kuelap, desde los años iniciales de la presencia española en los territorios de Chachapoyas. Justamente, el primer documento escrito que lo menciona es una petición hecha por Gonzalo Lucana quien en su condición de autoridad suprema de la parcialidad de Leimebamba, reclamó el año de 1558 para que los de Kuelap concurran al tambo de dicha parcialidad, porque allí les correspondía cumplir con sus tributos (Ruiz 2003). Sin embargo, un informe con detalles más precisos sobre la naturaleza e importancia del complejo arqueológico lo hizo Juan Crisóstomo Nieto el año 1843. Este magistrado en su condición de Juez de Chachapoyas, publicó en el diario oficial El Peruano de Lima, un informe con sus observaciones como resulta- 
do del viaje que había realizado a Kuelap para efectuar un deslinde de las tierras en el fundo de ese nombre. Al conocerse las notables e interesantes características del lugar, provocó la inquietud intelectual de varios estudiosos, quienes se hicieron presentes en el lugar para verificar y difundir, también, su trascendencia y complejidad. Pero ello ocurrió después de casi veinte años de haberse conocido el informe Nieto. Así tenemos que entre los aportes al mejor conocimiento de la importancia del sitio figuran Antonio Raimondi (1860), Arthur Wertheman (1870), Charles Wiener (1881), la Comisión de José Alayza (1892), Adolph Bandelier (1893), Philippe Kieffer (1910), Louis Langlois (1933), Henry Reichlen (1948), Hans Horkheimer (1957), Arturo Ruiz (1967) y Alfredo Narváez (1987) quien investiga Kuelap entre los años de 1985-1986-1987-19882000, 2004 ,2005, 2006, 2007 y 2008. Ellos centraron sus trabajos en el sitio, obteniendo nuevos conocimientos que aclararon importantes detalles sobre la arquitectura, la cronología, la estratigrafía arqueológica, y la real distribución de los conjuntos que integran el extenso complejo urbano de Kuelap. Existen, desde luego, muchas otras referencias como resultado de exploraciones y visitas a lo largo de la cuenca del río Utcubamba y sus afluentes, las cuales van ampliando el área de influencia de Kuelap y la extensión de las comunidades prehispánicas que habitaron la actual región de Amazonas. En años recientes varias áreas del antiguo territorio habitado por los distintos grupos de Amazonas han sido intervenidos y se han logrado provechosos informes para la comprensión del poblamiento humano en dicha región. Cabe citar al respecto los trabajos de Duccio Bonavia (1968),Waldemar Espinoza (1967),Warren Church (1986), Sonia Guillén (19 -2002 ), Adriana Von Hagen (1998-2000. 2002) Federico Kauffmann (1980-2003), Peter Lerche (1995-96), J. Mc Graw y otros (2001), Luis Mendoza (1998), Ruth Shady (1971), Inge Schjellerup (1997), Keith Muscutt (1998) y Ro- bert Bradley (2008). Pese a las referencias citadas quedan aun muchos aspectos todavía no tratados sobre las culturas que florecieron en Amazonas, como el referido a los patrones arquitectónicos de carácter funerario, las modalidades arquitectónicas y las expresiones alfareras que corresponden a las varias unidades sociales que poblaron su territorio. De igual manera, Kuelap, con ser el complejo donde se han realizado investigaciones intensivas desde hace ya varios años, permanece aún con muchas interrogantes, lo cual impide avanzar en los conocimientos sobre su historia.

Nuestras observaciones sobre la naturaleza del complejo arqueológico y de los sepulcros allí presentes, datan desde cuando realizamos excavaciones y exploraciones en el año de 1967, comisionados por el entonces Museo Nacional de Antropología y Arqueología de Lima, a las que se han añadido varias anotaciones como resultado de visitas posteriores. El informe sobre las excavaciones que realizamos en Kuelap fue presentado el año de 1972 como tesis para obtener el grado de arqueólogo en la Universidad Nacional Mayor de San Marcos, la cual contiene exclusivamente un estudio detallado de la estratigrafía descubierta y el análisis de la alfarería asociada, pero no de las sepulturas identificadas, ni de otros aspectos y hallazgos que hicimos en esa oportunidad. A fin de cumplir con la difusión de nuestras observaciones publicamos los datos presentes para complementar los informes anteriores.

\section{Antiguas sociedades en Amazonas}

Aún todavía no se ha llegado a un acuerdo sobre los grupos sociales que poblaron la región de Amazonas en tiempos prehispánicos. Se requiere investigar un mayor número de centros arqueológicos para obtener nuevas informaciones que confirmen los datos proporcionados por algunos documentos coloniales. De igual manera, conviene revisar al respecto, tales documentos escritos, con el propósito de hacer un deslinde acerca de los grupos humanos que habitaron en lo que actualmente 
constituye el área geográfica del Nororiente peruano, reconocido como la región Amazonas y su área de influencia. Hace algunos años Waldemar Espinoza Soriano, apoyándose en la información del cronista Garcilaso de la Vega, señaló el área geográfica y cultural de los chachapoya y, al mismo tiempo, añadió que el río Utcubamba separaba el área chacha de otros grupos étnicos. Entre esos otros grupos señalaba a los Luya y Chillao, localizados al Norte del territorio de los chachapoya y mas al Norte estaban los Paclas y Pomacocha. Hacia el Nor Este ubicaba a los Cascayunga. Hacia el Este situaba a los Charasmal y Jashallo. Al Sur Este, a los Cheduas, Alones, Choltos, Chillchos, Jivitos, Cholón y Quisupay y, finalmente, situaba al Nor este a los Sesuya y Rongia (Espinoza 1967). Pero, aparte de tomar lo informado por Garcilaso para el caso de los chachapoya, no existe, en cambio, la referencia o antecedente documental sobre los otros grupos. Sin embargo, aparecen algunos datos como para considerar que, en efecto, hubo otros grupos similares en muchos aspectos culturales a los Chachapoya. Tal como, por ejemplo, los Luya Chillao y los Chillcho, a los cuales se refieren los conquistadores como provincias, porque los consideraban en iguales condiciones a la de Chachapoyas (Lerche 1995: 111, Bueno 1950: 290, Schjellerup 1997, Espinoza 1967). Uno de aquellos grupos humanos de importancia fue justamente el de los Luya Chillao cuyos territorios comprendían un sector norte de la actual región de Amazonas, entre los ríos Utcubamba y Marañón, que puede coincidir con el área contemporánea de las actuales provincias de Luya y Utcubamba principalmente. De acuerdo al informe de Pérez de Astoas, la provincia de Luya y Chillaos se extendía incluso hasta los predios de Chachapoyas, Cheto y La Jalca (Pérez de Astoas 1762). Esta situación indica que el territorio de los Chachapoya estaba mas al sur, tal como, de modo general, lo grafican algunos mapas sobre la distribución de los grupos étnicos al oriente del río Marañón (Espinoza 1967, Schjellerup 1997).
De esto resulta que Kuelap se hallaba en la comprensión de los territorio de los Luya Chillao y así continua hasta el presente, siempre ubicado en la actual provincia de Luya.

Debemos anotar, asimismo, que los grupos humanos que poblaron Kuelap en tiempos prehispánicos, fueron el resultado de un largo proceso de ocupación cuyas más remotas raíces se puede profundizar hasta el período Precerámico, tiempo en el que ya estaban presentes antiguos grupos en áreas próximas a las nacientes de la cuenca del Utcubamba (Church 2004), aun cuando no sabemos todavía de otros asentamientos similares en otras partes de dicha cuenca, pero en nuestro concepto los hallazgos realizados por Warren Church constituyen un hito inicial acerca de la presencia humana en tiempos tan antiguos en la región de Amazonas. Para períodos posteriores, existen importantes evidencias que señalan la presencia humana en la cuenca del Utcubamba durante el Formativo como lo han mostrado los trabajos de Ruth Shady (Shady 1992). Pese a no haberse registrado aún hallazgos similares en la mencionada cuenca, los datos aportados indican una fuerte presencia de grupos humanos de este tiempo en las provincias de Bagua y Utcubamba desde hace 1300 años antes de Cristo. Pensamos que sobre la base de esas ocupaciones se desenvolvieron las posteriores agrupaciones humanas que dieron como resultado la constitución de varias organizaciones sociales que ocuparon los deferentes ambientes de la región de Amazonas, aproximadamente a partir del siglo II antes de Cristo. Tenemos entonces conocimiento que entre esas agrupaciones destacaron los Luya Chillaos, Chachapoya y Chillcho principalmente a quienes les tocó enfrentar las invasiones Inca y española a partir del siglo XV.

\section{Patrones Funerarios}

Las sepulturas identificadas se distribuyen tanto en el interior de la Fortaleza de Kuelap como fuera de ella, ubicadas en los otros sectores que 
comprenden la integridad del complejo. El ordenamiento que hemos realizado tiene como sustento la distinción de sus rasgos principales e igualmente su ubicación y la forma que ostentan. Las estructuras reconocidas en dichos sectores corresponden definitivamente a obras de carácter funerario por cuanto en todas ellas han aparecido restos de huesos humanos. Aparte, en otros sectores de la Fortaleza, se han identificado recientemente varios restos óseos humanos pero que no fueron sepultados en tumbas sino que son el resultado de haberlos dejado sin ninguna estructura que los cobije. De acuerdo a estas consideraciones tenemos los siguientes tipos:

\section{Sepulcros en nichos}

Estas tumbas se construyeron en el paramento externo de las altas murallas de contención de la Fortaleza, para lo cual extraían un sillar de dicha muralla y en el espacio desocupado colocaban el fardo funerario y las respectivas ofrendas (Fig. 1). Finalmente, las sellaban con piedras pequeñas unidas con barro. Extrajimos de una, los restos alterados de un contexto funerario que había sido saqueado, dejando sólo huesos humanos disturbados y retazos de tejidos de algodón sin decoración. Este tipo de tumbas se usaron cuando la Fortaleza de Kuelap ya estaba construida, y no se lo debe confundir con los restos óseos que aparecen en el relleno de las murallas, los cuales corresponden a tumbas mucho más antiguas, disturbadas al construirse la Fortaleza. Por la forma en que procedieron a extraer bloques de las murallas de contención y también del edificio conocido como El Torreón, para destinarlos a una tumba, pensamos que pueden ser los más tardíos debido a que tal procedimiento implicaría, en alguna manera, poner en peligro las estructuras que servían de matriz. Es probable que en otros conjuntos arqueológicos de la cuenca del Utcubamba aparezcan tumbas similares, pero al presente no se ha reportado otros casos. Fue Adolph F. Bandelier quien a princi- pios del siglo pasado observó en Kuelap este tipo de tumba y dejó anotado que "a lo largo de toda la pared, a cinco o seis pies del suelo, existen nichos funerarios cerrados con bloques de piedra. $\mathrm{Vi}$ muchos de esos nichos y obtuve en algunos cráneos humanos y huesos", luego afirma que tenían diferentes tamaños y que allí cabían cuerpos en cuclillas. Concluye ratificando que "las gentes de Kuelap practicaban la sepultura en nichos, en la gran pared que cubre el perímetro del farallón, por lo menos, en la mayoría de los casos." (Bandelier 1940: 34, 35).

Pero este tipo de nicho, difiere de similar elemento que identificamos en el complejo arqueológico de Sholón, al sur de Kuelap, en el actual distrito de Colcamar de la misma provincia de Luya (Ruiz 2005) donde existen nichos localizados en las paredes, con la diferencia de ser concavidades construidas especialmente para tal fin pero en el paramento interno de los recintos. A la luz de este dato, es posible que algunos restos de nichos que existen en Kuelap, hayan sido destinados a conservar los difuntos. La destrucción que ha soportado Kuelap durante su historia, no permite conocer muchos de los elementos arquitectónicos que lo componen. Sin embargo estamos en condiciones de afirmar que las tumbas en nichos construidos al interior de los paramentos de algunos edificios sirvieron como sepulturas. Deducimos este hecho de acuerdo a las anotaciones que se consignan en el primer informe escrito publicado sobre la naturaleza y magnitud del complejo arqueológico de Kuelap. Tales anotaciones las registró Juan Crisóstomo Nieto quien en su recorrido por la zona arqueológica, comprobó y registró la presencia de este tipo de tumba y la posición de los difuntos en ella. Afirmó que en los cuartos y en las murallas vio nichos donde: "están los huesos de los difuntos de la antiguedad: unos desnudos y otros envueltos en mantas de algodón muy tupidos aunque algo gruesas y todas labradas y con bordados de distintos colores". Y en cuanto a la 
posición de los difuntos comenta:" los doblaban haciendo que sus rodillas topasen con la punta de la barba, y sus manos se enredasen en las piernas, a la manera que habitamos en el vientre materno a los cuatro meses de nuestra formación" (El Informe Nieto 2007: 24). Otro dato al respecto, nos ofrece Ernest Middendorf quien anotó que: "No lejos de la entrada, y a ambos lados de esta, existen en la muralla, a poca altura sobre el suelo, pequeñas cavidades o nichos, a las cuales, mediante la extracción de uno de los sillares, se ha abierto un acceso. Algunos de estos nichos están vacíos, en otros hay todavía cráneos y otros huesos humanos, Parece que estos muros igual que rocas en otras partes, han servido de cementerio y que las tumbas como tantas otras han sido destruidas por los buscadores de tesoros"(Middendorf 1895).

\section{Chullpas}

Fueron erigidas sobre el piso de las plataformas de contención, a base de piedras y barro y están ubicadas junto a los recintos circulares. Se distinguen dos variedades de chullpas, una rústica de forma abovedada y planta circular, con una abertura en la parte inferior $y$, a veces, presentan una cornisa en el extremo superior (Fig. $\mathrm{N}^{\circ}$ ). Son las más numerosas, pues identificamos hasta cinco. La otra variedad en este tipo, es más elaborada y de mayores dimensiones, tiene planta en $\mathrm{D}$, de modo que la cámara sepulcral ocupa la parte posterior del edificio (Fig. $\mathrm{N}^{\circ} 2$ ). Las encontramos, una en el Pueblo Bajo y otra en el Pueblo Alto sobre la V Entrada. La chullpa del Pueblo Bajo, se levanta sobre una plataforma de baja altura que lo sustenta, conserva parte del techo con lajas y tenía fragmentos de revoque

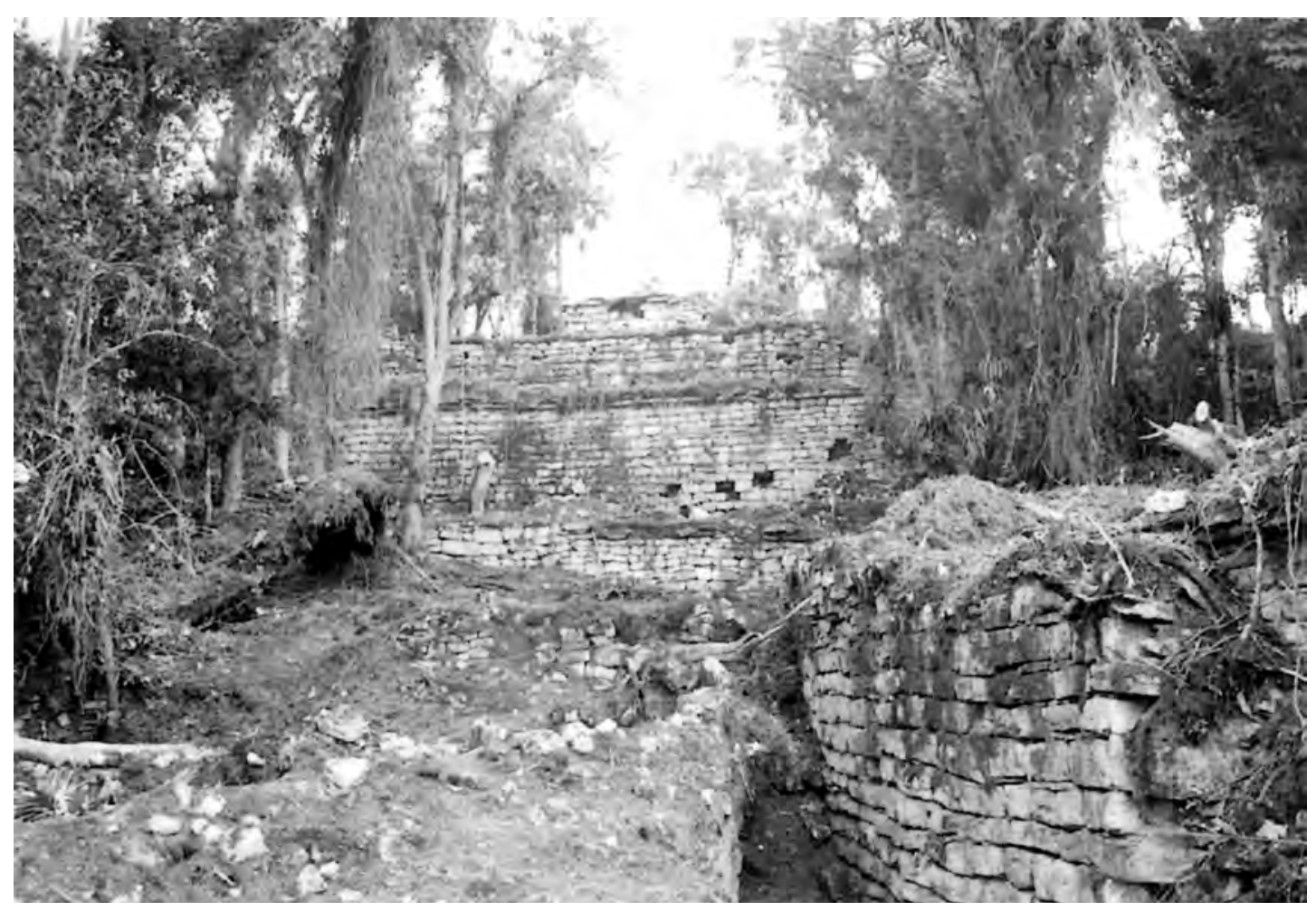

Figura 1. Vista del edificio denominado "El Castillo" del Pueblo Alto del complejo de Kuelap, compuesto por una estructura de tres cuerpos. En el frontis de la primera plataforma se observan varios nichos como efecto de haberse extraído los bloques para utilizarlos como tumbas. 
de barro en sus paredes con pintura en zigzag de color rojo sobre fondo crema. Por el hecho de estar construidas sobre el piso de las terrazas, colegimos que fueron edificadas evidentemente cuando la Fortaleza ya estaba concluida.

Una estructura con planta en D, similar a la del Pueblo Bajo de Kuelap, lo hemos registrado para los monumentos arqueológicos de Leymebamba, en el sitio actualmente denominado la Congona. (Ruiz 1985). Este lugar fue una sede importante del poblamiento aborigen, pues se menciona que en tiempo tardíos, es decir, durante el período de dominación incaica, allí residían los gobernantes de la región (Espinoza 1976). Eso explica probablemente la presencia de la estructura citada, que debe corresponder a un personaje de alta jerarquía. Chullpas similares, pero no iguales, han sido reportadas del sur de Leymebamba, en la zona de Atuen y quebradas vecinas, las que se atribuyen también a la conser- vación final de los restos humanos de personajes importantes (Schjellerup 1997).

La denominación que hemos adoptado con el término chullpa es para referirnos a la arquitectura funeraria aislada, edificada sobre el piso, como ocurre en las clásicas chullpas del Altiplano peruano boliviano, pero no adosada a grutas o acantilados como ocurre en el caso de los mausoleos o también en los sarcófagos. Desde luego que las chullpas de Kuelap no equiparan a las del área collavina, porque estas estructuras adquieren mayores dimensiones que aquellas. Carecen además de elementos decorativos tallados en los bloques como sí ocurre en las clásicas chullpas de Sillustani por ejemplo. Las chullpas de la segunda variedad para el caso de Kuelap tienen mas semejanza con estructuras similares del otro lado del Marañón, como aquellas de Chocta en la zona de Celendín ilustradas hace tiempo (Chavez 1976: Lám. 3, fotografía 5).

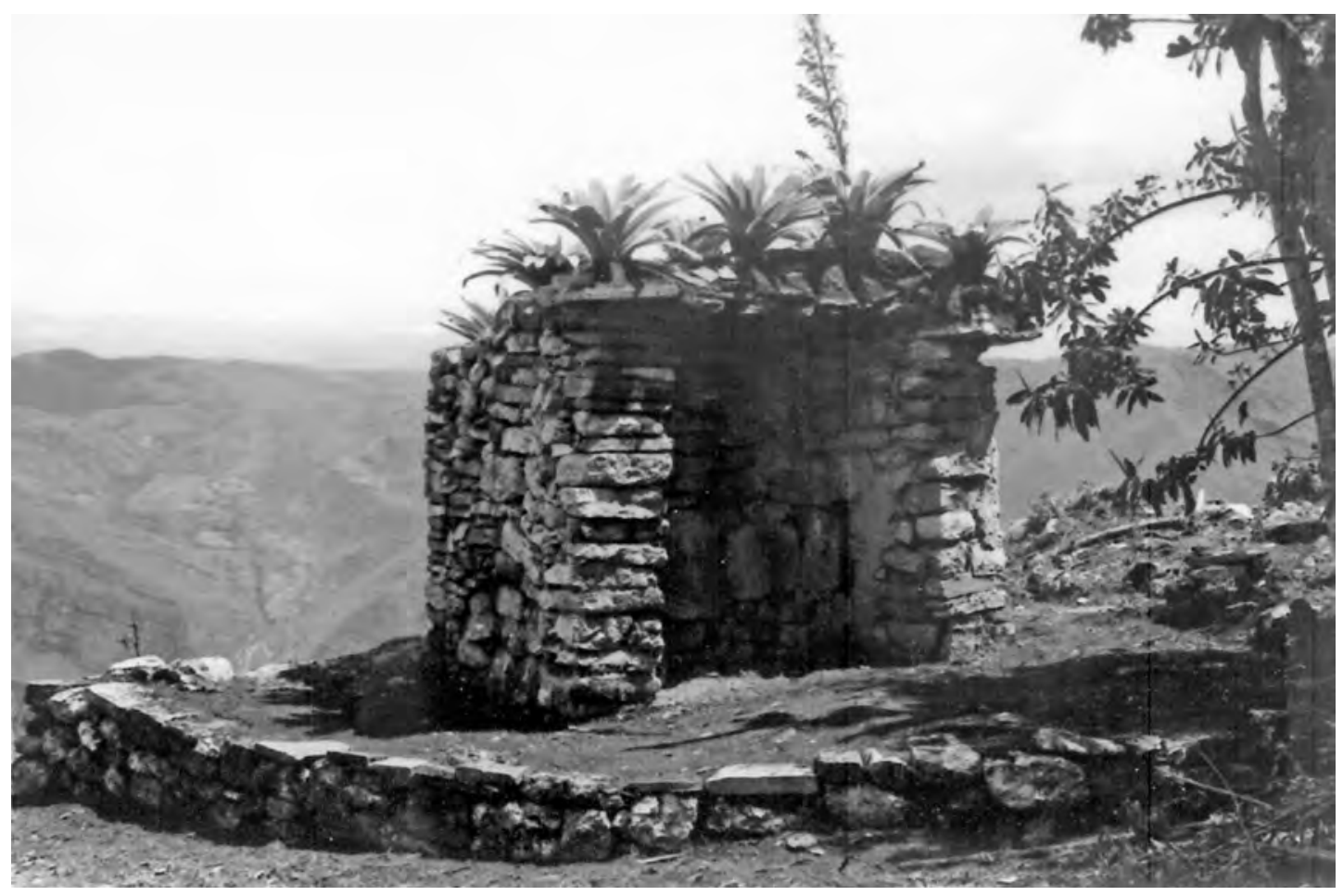

Figura 2. Chullpa, ubicada sobre una plataforma baja, al borde de la muralla de contención del Pueblo Bajo. Contenía los restos de un anciano. (Fotografía: A. Ruíz E.) 


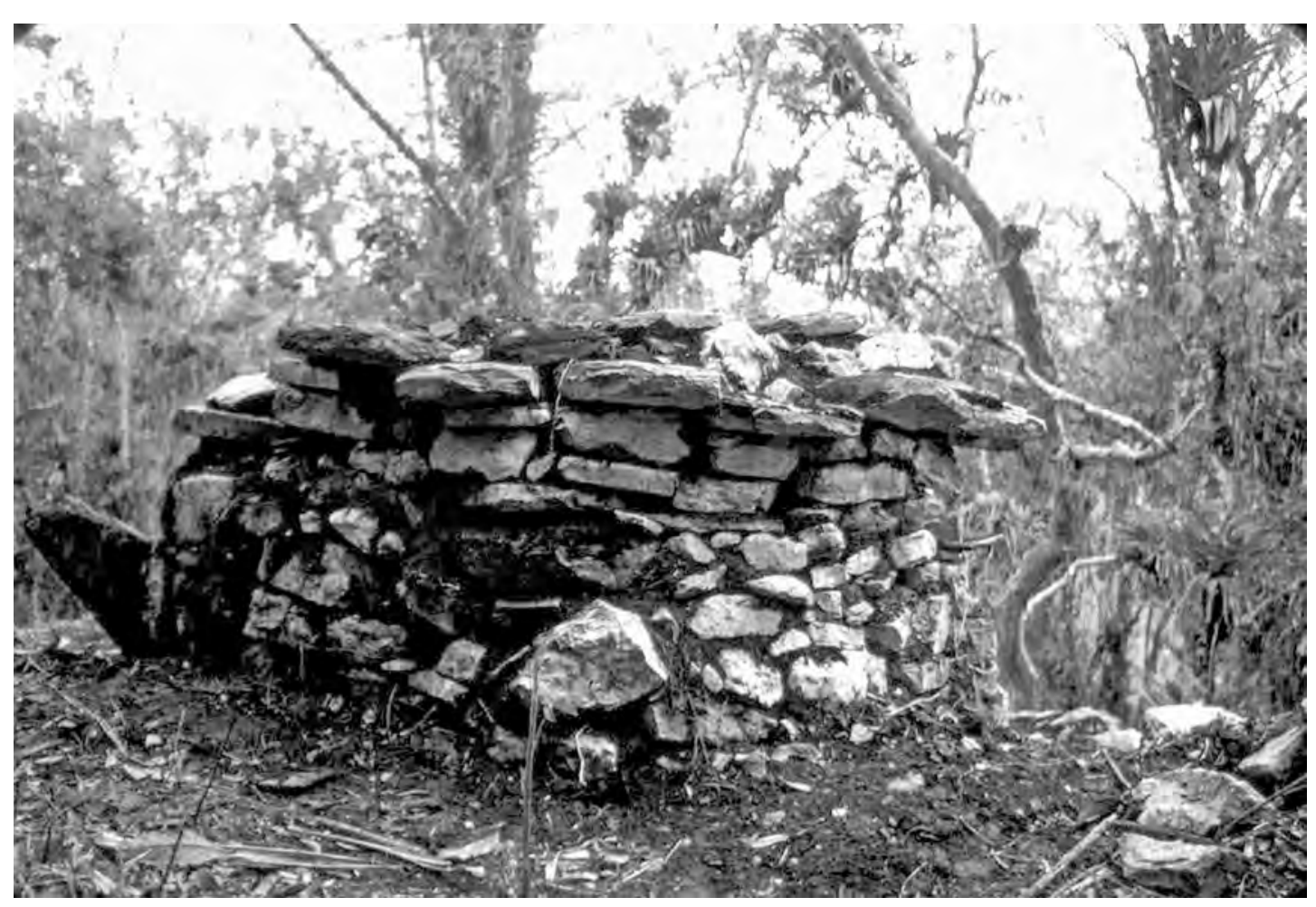

Figura 3. Chullpa de menores dimensiones, localizada al borde de Pueblo Alto de la Fortaleza de Kuelap. Tiene planta circular y conserva los aleros y parte del techo para lo que utilizaron lajas de piedra. (Fotografía: A. Ruíz E.)

\section{Fosas}

Presentan forma de tendencia circular, fueron cavadas en el piso, y tienen una cubierta de lajas y, por lo general, están revestidas de piedras. No son muy profundas ni espaciosas, de modo que sus dimensiones nunca exceden de un metro. Aparecen tanto al interior como al exterior de los recintos circulares y deben ser de la misma época que estos edificios y las tumbas tipo Chullpa. Es decir, habrían sido construidas cuando sus moradores prehispánicos desenvolvían su existencia en el mismo sitio. El hallazgo de este tipo de sepultura es frecuente en muchos otros conjuntos arqueológicos del valle del Utcubamba, donde aparecen asociados a los edificios circulares. Areas como la zona sur de Chachapoyas, donde se han realizado importantes investigaciones, han ofrecido evidencias de este tipo de entierros (Schjellerup1997).

\section{Sarcófagos}

Se trata de restos de sarcófagos, ubicados en los acantilados del frente occidental del macizo de Kuelap, distribuidos en dos sectores. Uno, es el sitio denominado La Petaca (fig. 4), donde aparecen restos muy disturbados, asociados a huesos humanos. Lo único que se observa son prácticamente los cimientos distribuidos en hilera el borde del abismo, posición que es característica en este tipo de sepulturas. Dichos cimientos tienen planta circular y pueden haber pertenecido a los sarcófagos simples o a los antropomorfos. La Petaca ocupa un gran abrigo rocoso, en el abismo occidental del macizo de Kuelap, al cual se tiene acceso por la III Entrada de La Fortaleza, debido a que por este sector, el abismo no es muy escarpado. El otro sector con sarcófagos está ubicado en un farallón de pendiente extrema, al Norte de La Fortaleza, en una parte inter- 


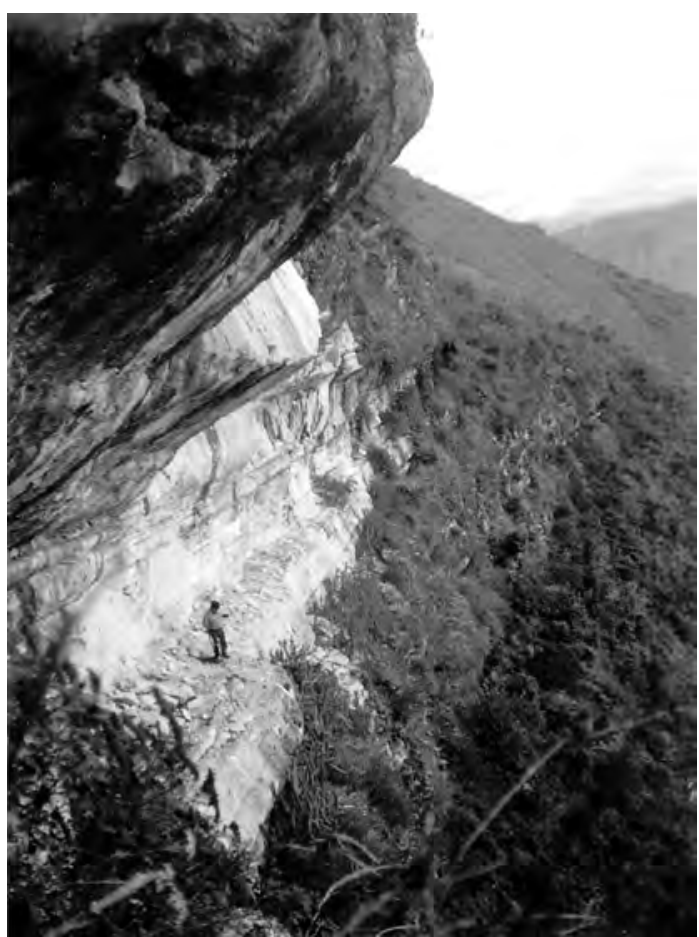

Figura 4. La Petaca, abrigo rocoso ubicado al pie de la muralla occidental de la Fortaleza de Kuelap. Aquí se han identificado varios restos de sarcófagos de los que sólo quedan los cimientos de tales estructuras funerarias. (Fotografía: A. Ruíz E.)

media, entre el pie del Torreón de la Fortaleza de Kuelap y el sector denominado La Fila. Apreciamos aquí, varios restos de sarcófagos que se hallan mejor conservados que los de La Petaca, entre los cuales, dos de ellos conservan la base y parte del cuerpo que es de forma cónica (Fig. 6). Uno de estos muestra estar decorado con un diseño similar al de los cuatro sarcófagos centrales del Grupo 1 de Karajía . La decoración es de color rojo oscuro sobre fondo crema a base de bandas verticales angostas que semejan plumas, distribuidas en el torso del sarcófago. Este sarcófago tiene un madero central rollizo que probablemente servía para sostener la falsa cabeza de barro, con la cual complementaba el sarcófago antropomorfo. De acuerdo a sus características correspondería al denominado como de Categoría A, en la morfología anunciada por F. Kauff- mann (2003). Los sarcófagos están distribuidos en pequeños abrigos y emplazados a distintas alturas, hecho que difiere de los del sector anterior, en el cual aparecen más bien alineados.

Una de las primeras exploraciones que se realizó en Kuelap por parte de Juan Crisóstomo Nieto dio referencias sobre la existencia de este tipo de sepulturas. Nos enteramos de ello, cuando el referido autor anunció que: "También se encuentran otras sepulturas que parecen unos hornos pequeños de 6 pies de alto y 24 o 30 de circunferencia, en cuya base hay una loza y sobre ella los restos de algún hombre o mujer".

Añade luego que llegaron a lo que debe ser el abrigo de La Petaca donde actualmente se observan restos de sarcófagos pues dice: "llegamos a un hueco formado por las peñas que nacían del cerro, en el cual había 10 bultos de huesos humanos, perfectamente conservados, envueltos en sus mantas, de los cuales uno que era de hombre de edad, estaba cubierta con una manta de pelo" (El Informe Nieto 2007: 25). Esas sepulturas en forma de hornos es lo que nosotros pudimos observar justamente en el abrigo rocoso de la Petaca, donde actualmente se presentan las huellas tan solo de los cimientos de esas pequeñas estructuras con algunos huesos al interior. Son los vestigios de los sarcófagos que allí existieron (fig. 5).

En términos generales, este tipo de tumba, se observa en varios lugares de la cuenca del Utcubamba y en forma muy especial en las cumbres y laderas de su margen izquierda, en lo que comprende la actual provincia de Luya de la región de Amazonas. Tanto la forma como la ubicación que tienen es parecida en todas ellas, tal como lo muestra el más difundido y conspicuo conjunto de sarcófagos de Karajía (Kauffmann 2003) cerca del pueblo de Cruzpata y el reciente dato de Sholón ubicado en el distrito de Colcamar, así como el de Tamuya, ambos de la provincia de Luya (Ruiz 2005, 2006). Este tipo de sepultamiento, por razones de su distribución geográfi- 


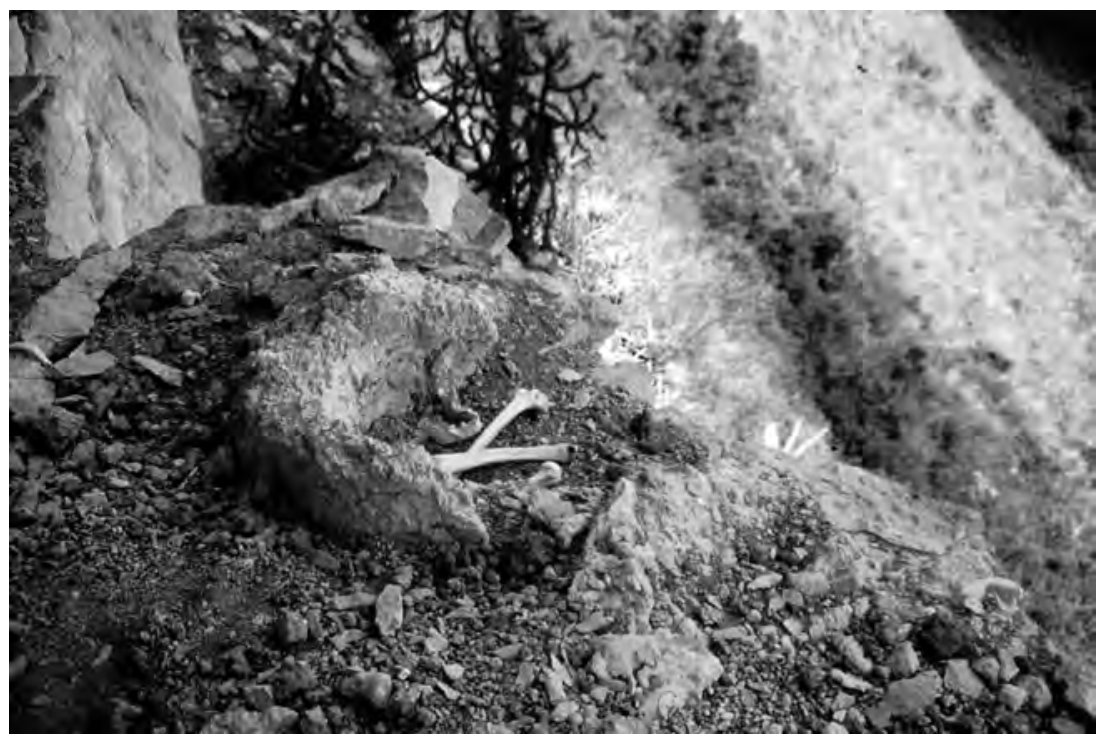

ca, centrada en la provincia de Luya corresponde a lo que en tiempos coloniales fue reconocido como la antigua provincia de Luya y Chillao, de similar categoría social y política que los chachapoya durante la época prehispánica y que puede distinguirse de éstos, precisamente por un patrón funerario diferente- los sarcófagos-, aunque ambos mantuvieron prácticamente similares rasgos en algunos otros aspectos culturales de las sociedades que florecieron en Amazonas

\section{Mausoleos}

Se ubican en el sector llamado La Barreta, en el acantilado Norte del macizo de Kuelap. Puede apreciarse allí dos estructuras como incrustadas en las grietas del cerro, construidas a base de piedras con facetas rectangulares unidas con barro (Figs. 7, 8). Entre ambas estructuras se conserva todavía un palo clavado en la peña, por cuyo motivo los lugareños lo denominaron La Barreta, atribuyéndole relatos míticos (Ruiz 2000). Una de las estructuras tiene la pared curva y es de

Figura6. Restosdeunsarcófagolocalizadoenel acantilado del lado occidental de la Fortaleza de Kuelap. Se observa la base, el alero y la parte frontal del propio sarcófago.

(Fotografía: A. Ruíz E.)
Figura 5. Restos de sarcófagos destruidos en el abrigo de La Petaca al pie de la Muralla Occidental de la Fortaleza de Kuelap. Se observa la base de las tumbas y algunos restos óseos humanos. (Fotografía: A. Ruíz E.)

difícil acceso, en tanto que la otra muestra su pared recta y permite observar con dificultad la parte interna. La pared externa de ambas estructuras exhiben, como elemento distintivo, una hilera de pequeños nichos rectangulares que cumplen función decorativa. Al pie del barranco observamos huesos humanos que han caído justa-

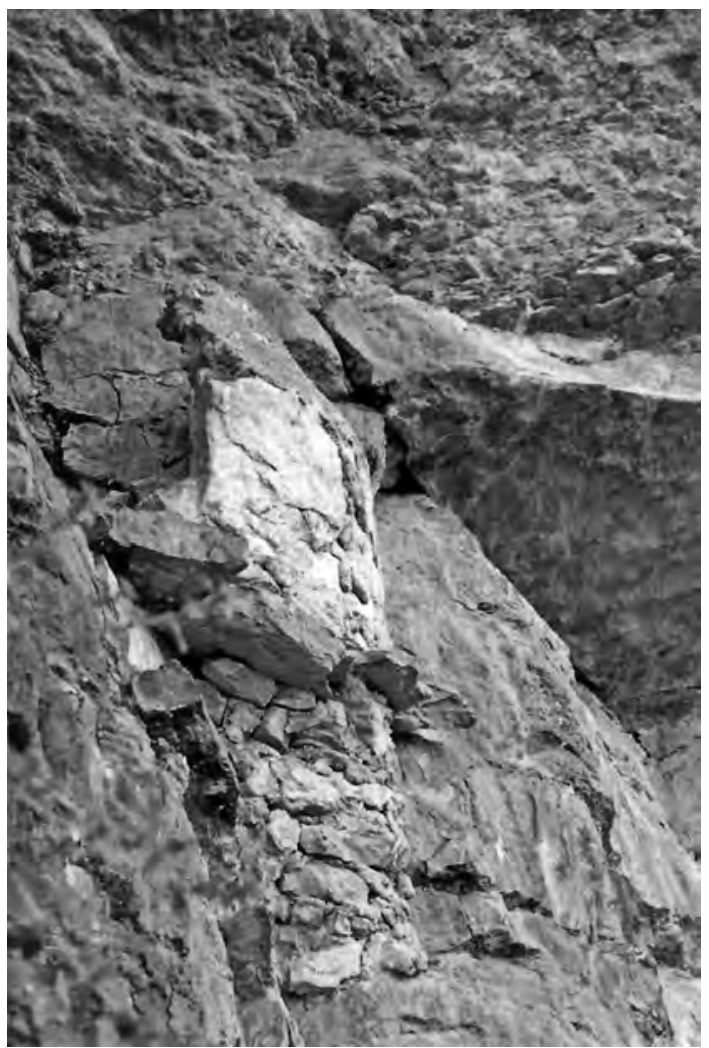


mente de uno de los mausoleos. Este tipo de monumentos funerarios, se distribuye en varios lugares de Amazonas como prendidos en abrigos de acantilados abismáticos que, en ciertos casos, eran preparados artificialmente, con variaciones en los elementos decorativos en sus muros y por que en algunos lugares, se hallan asociados con cierta frecuencia a dibujos rupestres. Los mausoleos de Kuelap, por sus características básicas se relacionan, por ejemplo, con los de la Laguna de los Cóndores (Hagen y Guillén 1996), con los de la zona de Atuén al sur de Chachapoyas (Muscutt 1998), con la del Valle de los Chillchos y los del valle del río Huabayacu (Lerche 1995, 2000), Revash en el valle de Santo Tomás (Reichlen 1950) aunque en este caso la cubierta de los mausoleos aparece con un techo a dos aguas. El sitio de los Pinchudos ofrece una muestra de este tipo de mausoleos pero con una elaborada decoración mural (Bonavia 1998: 94-95; Kauffmann 1980, 1997, 2003). A este tipo de tumba se lo ha denominado también como Chullpa, al tratar sobre las dos modalidades de arquitectura funeraria de los Chachapoya (Hagen 2002).

$\mathrm{Al}$ parecer este tipo de tumba fue observado también por Juan Crisóstomo Nieto, en la exploración que hizo de Kuelap, por lo cual dejó anotado que: "y habiendo subido como 600 pies nos hallamos imposibilitados de pasar adelante a causa de una peña perpendicular que no permitía el acceso a una pared de ladrillos de piedra con sus ventanillas que distaría del punto donde se pudo llegar como 60 pies y por la falta de escalera y de tiempo no vimos lo que se contenía en esta pared que está en una elevación que da vista al Oriente, Norte y Occidente, hasta donde los ojos del hombre alcanzan" (Nieto 2007: 26). Como se puede observar en concordancia a la breve descripción que ofreció existe coincidencia en su apreciación sobre el sitio que actualmente se conoce como La Barreta.

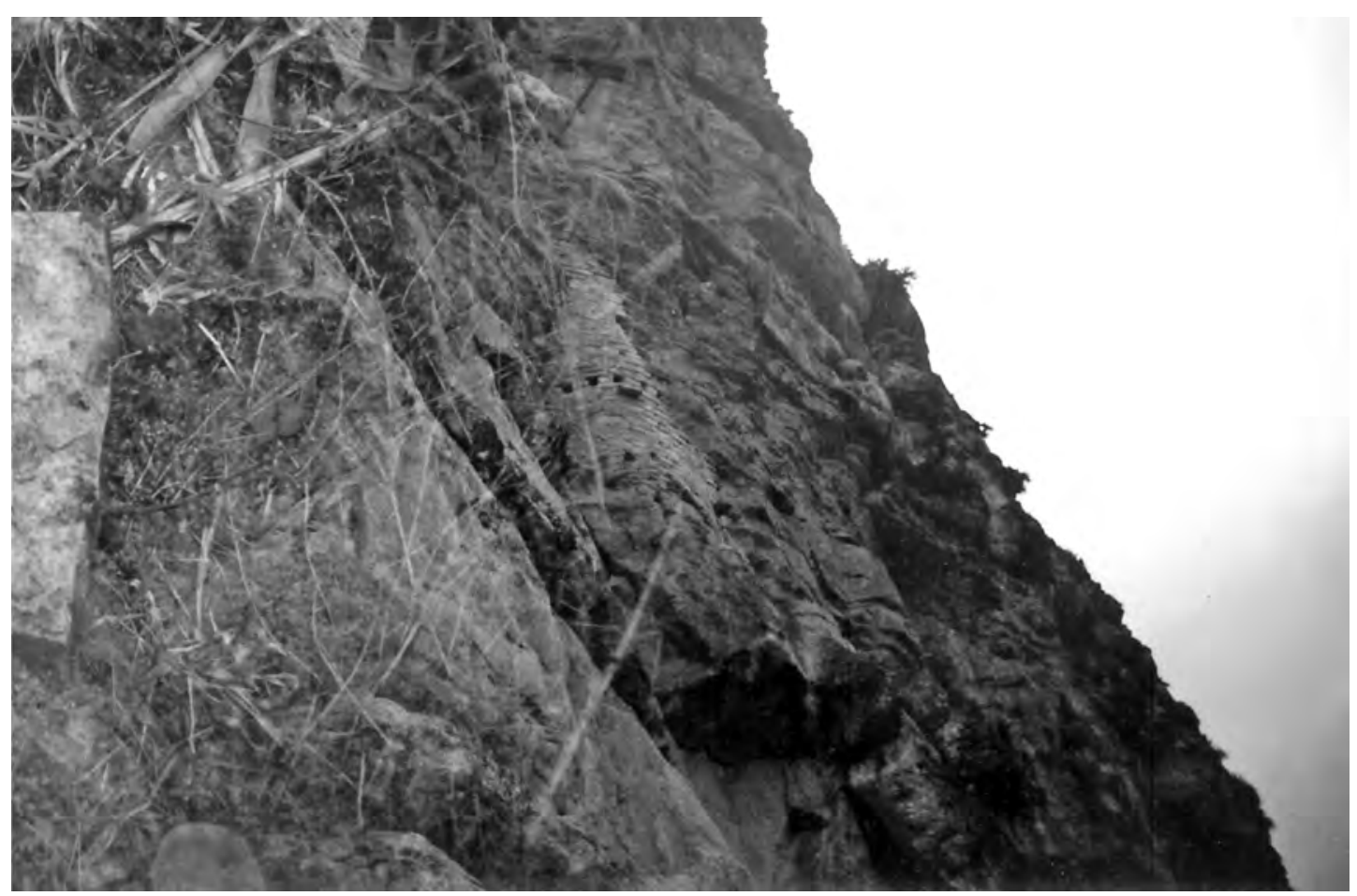

Figura 7. Vista de un Mausoleo construido en el acantilado de La Barreta. El paramento externo de la pared muestra varios nichos pequeños. (Fotografía: A. Ruíz E.) 


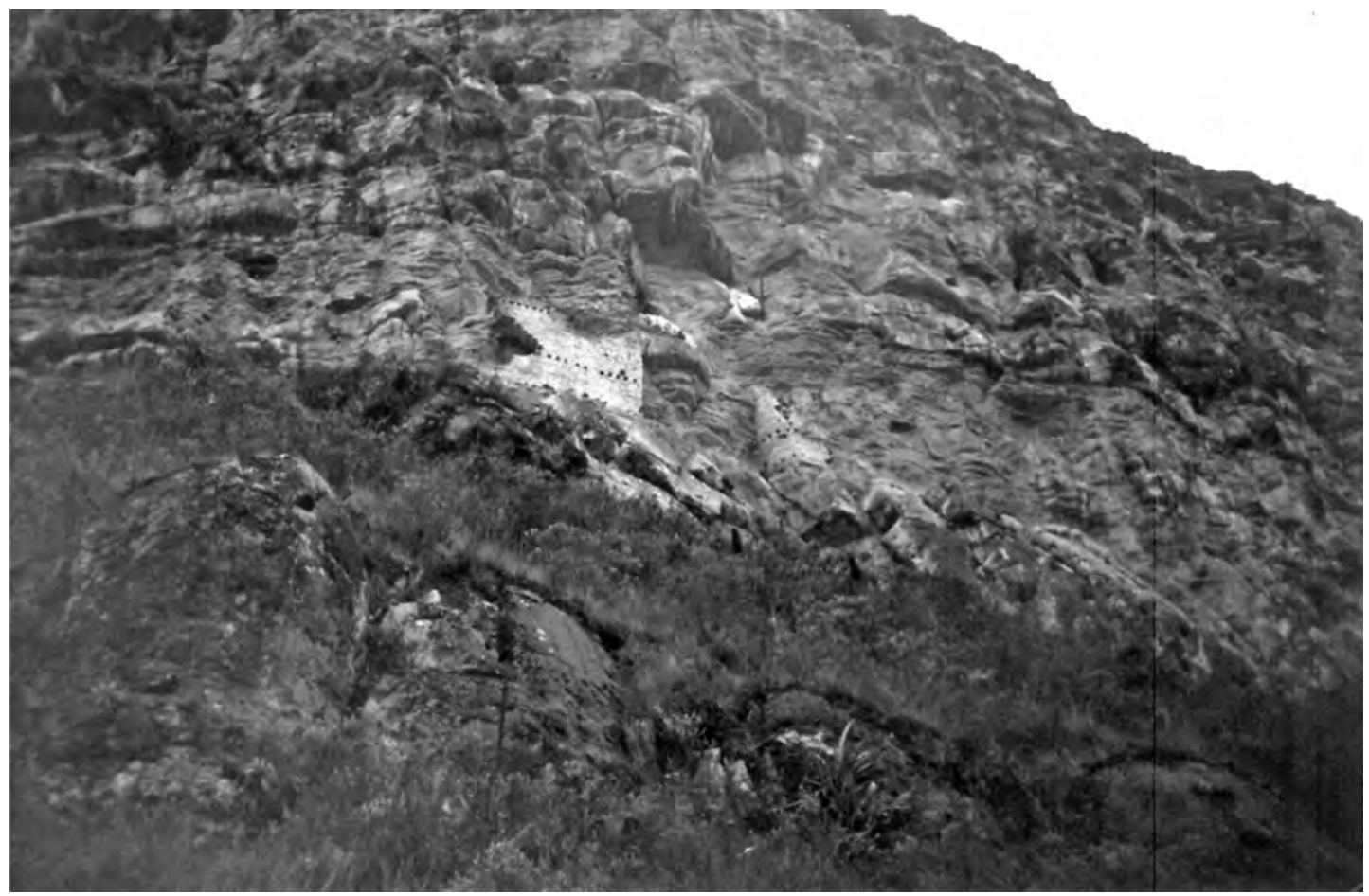

Figura 8. Vista panorámica del acantilado de la Barreta, donde se localizan dos Mausoleos o edificaciones prendidas de la pared rocosa. (Fotografía: A. Ruiz E.)

\section{Grutas funerarias}

Se ubican hacia el sector denominado Cruz Pata, a inmediaciones del camino de herradura que se dirige de Kuelap al pueblo de El Tingo. Están cubiertos de arbustos y su acceso no es dificultoso por cuanto se halla a nivel del camino y no en un abismo, lo cual lo diferencia de las grutas que contienen mausoleos y sarcófagos ubicados en altos acantilados. Son grutas pequeñas no muy profundas y de poca altura, que las habían utilizado como osarios, en cuyo piso se observan numerosos huesos humanos semienterrados y, al mismo tiempo, desarticulados. Es posible que estos huesos correspondan a bultos cubiertos con telas en forma de fardos pero no hemos encontrado indicios de tales indumentos. Al parecer, su profanación debió haber ocurrido hace bastante tiempo, por cuya razón se hallan semienterrados y no se observan en la superficie, objetos de naturaleza diferente a los restos óseos huma- nos. Aunque estas grutas son pequeñas, pero tienen relación con varias otras grutas y cavernas distribuidas en la región de Amazonas, donde existen los restos de entierros, hoy convertidos en osarios, por efecto de la depredación.

En el área de Kuelap, existen otras cavernas donde, sin embargo, no hemos observado que se hayan utilizado como lugares de enterramiento. Tales cavidades son las de El Subterráneo donde más bien corre un arroyuelo que genera un ambiente húmedo no apto a la conservación de momias. La otra es El Murciélago que por ser de poca dimensión tampoco muestra vestigios de haber sido un cementerio.

\section{Discusiones}

De acuerdo a lo descrito, planteamos que en Kuelap se encuentran los principales tipos básicos de sepulcros prehispánicos distribuidos en la actual región de Amazonas. Por ende, están presentes los diversos tipos de sepulturas iden- 
tificadas en otras áreas del territorio ocupado por los antiguos grupos humanos Chachapoya, Luya y Chillao y Chillcho. Esta situación confiere al complejo arqueológico de Kuelap una especial importancia para estudiar las costumbres funerarias de sus antiguos pobladores, dilucidar la antigüedad de esas modalidades mortuorias y aproximarse al culto y los rituales dedicados a los ancestros. Los tipos de tumbas en nichos, en chullpas y las soterradas se construyeron cuando la Fortaleza ya estaba concluida, por el hecho de estar erigidas sobre estructuras ya terminadas. Es posible que los sepultamientos en sarcófagos, en mausoleos y los entierros en grutas se hayan realizado también cuando la Fortaleza se encontraba en pleno apogeo. Un nicho que descubrimos en la muralla, contenía huesos largos flexionados, retazos de telas y soguillas, lo cual indica que los difuntos fueron depositados con las extremidades replegadas al cuerpo, envueltos en telas de algodón y sujetados con soguillas para evitar que perdiesen la posición en la cual fueron enterrados. La posición de los difuntos en los otros tipos de sepulturas también repitieron el mismo modelo, debido al tamaño de éstas, que no permitían dejar los cuerpos extendidos. Algunos fragmentos de alfarería asociados, revelan la presencia de ofrendas. Ejemplos como los de la Laguna de los Cóndores en el área de Leimebamba (Hagen y Guillén 1997) y Carpona cerca de Montevideo (Ruiz 2002), confirman la costumbre de acompañar a los difuntos con algunos objetos que estaban ligados a sus ideas que trascendían la vida. Probablemente, los tipos de tumbas que hemos identificado en Kuelap corresponden a individuos de distinta categoría social, pues existen, obviamente, diferentes niveles de inversión laboral para construirlas. Como se observa, por ejemplo, en los sarcófagos, en los mausoleos y en las chullpas con planta de D, una de ellas con plataforma. Es interesante también notar la distinta ubicación de las tumbas, pues se dio mayor seguridad a los sarcófagos y mausoleos, porque los colocaron en acantilados abismáticos de difícil acceso, en razón, tal vez, a su mayor prestigio. Pero la mayor frecuencia de tumbas corresponde a los tres primeros tipos mencionados arriba. La variedad y la cantidad de tumbas existentes en Kuelap, indica que existió la práctica de un culto diferenciado y muy arraigado a los ancestros. Sugiere también que el grupo humano que pobló Kuelap fue una sociedad compleja, lo cual se testifica, asimismo, con la complejidad arquitectónica de las edificaciones. Se observan al respecto, edificios con decoración mural, numerosos edificios sencillos sin ornamentación mural, construcciones singulares como el Tintero, el llamado Castillo, el Torreón y pocas estructuras rectangulares.

Los tipos de tumba enunciados reflejan que el grupo social que habitó Kuelap en tiempos prehispánicos tenía la concepción de preservar a los difuntos, porque construían o elegían para dicho propósito, un sitio especial para enterrarlos. Es decir, no apelaron a desaparecer totalmente a los difuntos si no más bien los tenían cerca, sea dentro de sus recintos o próximos a ellos. Para otras culturas se conoce que la costumbre era desaparecer totalmente a los muertos, llegando incluso a cremarlos como ocurre, por ejemplo, en algunos grupos de nuestra sociedad contemporánea. Es más, entre los kuelapinos prehispánicos, un tipo de tumba, el de los sarcófagos, imitaba la forma humana, si observamos el ejemplo emplazado en el acantilado de Kuelap que aunque incompleto, tiene todos los rasgos de los sarcófagos antropomorfos de Karajía y de otros similares de la provincia de Luya. Este hecho implica comprender que las tumbas de nuestro estudio evidencian que los antiguos grupos humanos de Kuelap conceptuaban la necesidad de tener a los muertos cerca del lugar donde desenvolvían su vida cuotidiana. Y, probablemente, los personajes de importancia en su comunidad, merecían ser conservados en cápsulas o sarcófagos a los que daban forma humana, para, de esa manera, hacerlos más ostensibles. Así, los muertos no estaban ausentes en el trajinar diario de la sociedad, porque debieron continuar ejerciendo su influencia y, tal vez, guardaban sus prerrogati- 
vas como las habían tenido en vida. También es importante notar que los sarcófagos solo están localizados en el antiguo territorio de la provincia de Luya, lo cual nos permite afirmar que este tipo de sepultamiento fue exclusivo de esta zona, pues no se ha reportado hasta el presente que ellos existan entre los otros grupos de Amazonas como los Chachapoya, Chilchos,y demás unidades sociales. Esto implica que hubo algunas diferencias entre esos grupos humanos y por eso es que cuando llegaron los españoles cada uno de ellos expresó su identidad al referirse a los curacazgos al que estaban adscritos. El curaca de los Chilchos que ya estaba cristianizado manifestó que él era don Fernando Chilcho y obviamente no dijo ser Chachapoya. Cosa similar ocurrió con los de Luya y con los Chillao. O sea, ambos curacas estaban al mismo nivel pues el título de las encomiendas que se otorgó al capitán Alonso de Alvarado en 1538 puntualizaba: "Por la presente, en nombre de Su Majestad, os encomiendo el cacique principal de los Chachapoyas que se llama Guamán, con todos sus indios principales e pueblos subjetos. Y asimismo el cacique de Chilcho, con sus indios e principales e sus subjetos" (Espinoza Soriano 1967: 285). Los españoles llegados a los territorios amazonenses en el siglo XVI comprendieron bien la distribución de las diferentes unidades sociopolíticas y en razón de ello fueron creando las encomiendas respetando los curacazgos existentes.

El hecho de haber construido los diversos tipos de tumbas al interior de la Fortaleza, o bastante próximas a ella, nos está indicando la especial importancia que tenías tales difuntos para merecer esa distinción. Porque sus ocupantes antiguos debieron haber considerado un rango social superior a quienes así los sepultaban a diferencia de otras tumbas que las ubicaron fuera de la Fortaleza como aquellos enterrados en simples grutas. Podemos argumentar entonces la existencia de una clara jerarquía en la sociedad de esos tiempos, asunto que de igual manera se ha opinado para sociedades como los Guánuco para quienes se escribió "que aquellos que fue- ron escogidos para permanecer al interior de la comunidad de los vivos, gozaban sin duda de un estatuto especial y de un poder sagrado superior"( Bonnier 1996:39).

\section{BIBLIOGRAFÍA}

Bandelier, Adolph

1940 Los indios y las ruinas aborígenes cerca de Chachapoyas en el Norte del Perú. Chaski, Vol. 1, № 2. Lima.

Bonavia, Duccio

1998 "La colonización incaica de la Selva Alta”. Arkinka, Revista de arquitectura, diseño y construcción. Año 3, $\mathrm{N}^{\circ}$ 34. Lima.

Bonnier, Elizabeth

1999 "Morfología del espacio aldeano y su expresión cultural en los Andes Centrales". Arqueología Peruana 2. Arquitectura y Civilización en los Andes Prehispánicos. Sociedad Arqueológica Peruano-Alemana.

Bradley, Robert

2008 The Architecture of Kuelap. The Art and Architecture of the Precolumbian Chachapoya. VDM Verlag.

Chavez, Moisés

1976 “Arqueología de Celendín”. En Cuadernos de Arqueología Andina. Boletín de la Fundación "Josefina Ramos de Cox". No. 1. Lima.

Church, Warren

1992 "Investiagciones arqueológicas en el Gran Pajatén: 1985-1986. Ponencia presentada al Simposio: Biodiversidad, historia cultural y futuro del Parque Nacional del Río Aviseo. 17 al 20 de agosto. Lima.

1996 Prehistoric Cultural Development and Interregional Interaction in the tropical montane forests of Peru. Yale University. 2 t. Tesis de doctorado.

2004 "Manachaqui: Buscando las raíces de los Chachapoya". En SIAN Revista de Arqueología. Año 9. Edición $N^{\circ} 15$. Trujillo 


\section{EL INFORME NIETO}

2007 El Informe Nieto y otros documentos históricos sobre Kuelap 1818-1843. Gobierno Regional de Amazonas-Dirección Archivo Regional de Amazonas. Chachapoyas.

Espinoza Soriano, Waldemar

1967 "Los señoríos étnicos de Chachapoyas y la alianza hispano-chacha”. Revista Histórica, Tomo XXX. Lima.

Hagen, Adriana von y Sonia Guillén

1996 “Tombs with a View”. En Archaeology, March/April.

Hagen, Adriana von

2002 Los Chachapoya y la Laguna de los Cóndores. Lima Perú.

Kauffmann, Federico

1980 "Los Pinchudos: Exploraciones de Ruinas Intactas en la Selva". Boletín de Lima, $\mathrm{N}^{\circ} 7$,pp. 26-31.

1997 "Los Mausoleos de la Laguna de las Momias. y otros de la cultura Chachapoyas(s)". Arkinka, Revista de Arquitectura, Diseño y Construcción. Año 2, $\mathrm{N}^{\circ}$ 24. Lima.

2003 Los Chachapoya(s). Moradores ancestrales de los Andes Amazónicos Peruanos. UAP. Universidad Alas Peruanas. Lima

Kaulicke, Peter

2000 Memoria y Muerte en el Perú Antiguo. Pontificia Universidad Católica del Perú. Fondo Editorial. Lima.

Lerche, Peter

1995 Los Chachapoya y los Símbolos de su historia. Lima.

1999 Quest for the Lost Tombs of the Peruvian Cloud People. National Geographic 198/3:63-81.

Middendorf, Ernest W.

1895 Peru. Betrachtungan und Studien. T. III. Berlín.

Muscutt, Keith

1998 Warriors of the Clouds. University of New Mexico Press. Albuquerque.

Narvaez, Alfredo

1987 "Kuelap una ciudad fortificada en los
Andes Nor-Orientales de Amazonas, Perú”. En Simposium Arquitectura y Arqueología. Pasado y futuro de la construcción en el Perú. Universidad de Chiclayo,pp.115-142, Chiclayo Perú.

Reichlen, Henry y Paule Reichlen

1950 "Recherches archeologiques dans les Andes du haut Utcubamba". Journal de la Societé des Americanistes. Tomo XXXIX:219-251.

Ruiz, Arturo

1985 "Los monumentos arqueológicos de Leymebamba”. En Boletín de Lima, $\mathrm{N}^{\circ}$ 42, Año 7. Lima.

2000 "La Barreta de Oro: Creencia popular en Kuelap". En El Torreón, Lima Enero.

2002 "Carpona: Complejo Funerario de Montevideo en Chachapoyas". En El Torreón, Año 6, $\mathrm{N}^{\circ}$ 66. Lima, Dciembre-Enero.

2003 Guia Arqueológica de Kuelap. Lima.

2005 "Sholón: Un complejo arqueológico en Colcamar, Amazonas". En Unay Runa 7. Revista de Ciencias sociales Una publicación del Instituto Cultural Runa. Lima.

2006 "Los Sarcófagos Antropomorfos de Tamuya”. En El Torreón, Julio-Agosto. Lima.

Schjellerup, Inge

1997 Incas and Spaniards in the conquest of the Chachapoyas, Archaeological and Ethnohistorical Research in the North-eastern Andes of Peru. GOTARC, series B. Gothenburg Archeological Theses, 7. Göteborg University.

Shady, Ruth

1971 Bagua, una secuencia del período Formativo en la cuenca inferior del Utcubamba. Tesis de Bachillerato, Universidad Nacional Mayor de San Marcos. Lima.

1992 "Sociedades Formativas del nororiente peruano". En Prehistoria Sudamericana. Nuevas Perspectivas. Ed. Betty Meggers. Taraxacum. Washington. 